\title{
REV-ERB $\alpha$ reduction is associated with clinicopathological features and prognosis in human gastric cancer
}

\author{
XIAOSHAN WANG ${ }^{1}$, NANA WANG ${ }^{2}$, XIANG WEI $^{3}$, HAOYUAN YU $^{1}$ and ZHENGGUANG WANG ${ }^{1}$ \\ ${ }^{1}$ Department of General Surgery, The First Affiliated Hospital of Anhui Medical University; \\ ${ }^{2}$ Laboratory of Pathophysiology, School of Life Sciences; ${ }^{3}$ Laboratory of Molecular Biology, \\ Department of Biochemistry, Anhui Medical University, Hefei, Anhui 230032, P.R. China
}

Received October 22, 2017; Accepted April 13, 2018

DOI: $10.3892 / \mathrm{ol} .2018 .8809$

\begin{abstract}
Gastric cancer is a serious threat to human health. Nuclear receptor subfamily 1 group D member 1 (REV-ERB $\alpha$ ) is a member of the nuclear hormone receptor family that regulates lipid metabolism, inflammatory responses and circadian rhythms. However, the role of REV-ERB $\alpha$ in the pathogenesis of human gastric cancer is unclear. The present study employed gastric cancer tissues from 74 patients and determined the association between REV-ERB $\alpha$ expression with clinicopathological variables and prognosis. Furthermore, the association between REV-ERB $\alpha$ and apoptosis in undifferentiated and moderately differentiated human gastric cancer cells was determined. It was identified that REV-ERB $\alpha$ expression was decreased in gastric cancer, which was positively associated with poor differentiation $(\mathrm{P}=0.009)$, $\mathrm{T}$ stage $(\mathrm{P}=0.001)$, Tumor-Node-Metastasis $(\mathrm{TMN})$ stage $(\mathrm{P}=0.001)$ and lymph node metastasis $(\mathrm{P}=0.007)$. In the survival analysis, the 3 - and 5-year survival times of patients were significantly associated with $\mathrm{REV}-\mathrm{ERB} \alpha$ expression $(\mathrm{P}=0.009$ and $\mathrm{P}=0.002$, respectively). Low REV-ERB $\alpha$ expression was associated with poor prognosis $(\mathrm{P}<0.05)$. Concurrently, cleaved caspase-3 expression was downregulated, whereas expression levels of Bcl-2 and the $\mathrm{Bcl}-2 / \mathrm{Bax}$ ratio were upregulated in gastric cancer tissues compared with normal tissues. REV-ERB $\alpha$ activator GSK4112 caused apoptosis in SGC-7901 and BGC-823 cell lines. REV-ERB $\alpha$ levels were decreased in human gastric cancer, which was associated with poor differentiation, TMN stages and poor prognosis. REV-ERB $\alpha$ is a potential biomarker for tumor development and prognosis, and a potential therapeutic target for gastric cancer.
\end{abstract}

Correspondence to: Dr Zhengguang Wang, Department of General Surgery, The First Affiliated Hospital of Anhui Medical University, 81 Meishan Road, Hefei, Anhui 230032, P.R. China

E-mail: wangzhengguang@ahmu.edu.cn

Key words: nuclear receptor subfamily 1 group D member 1, gastric cancer, biomarker, prognosis, apoptosis

\section{Introduction}

Gastric cancer is the most common cancer, with the fourth highest incidence rate of all gastric adenocarcinomas and $>723,000$ mortalities every year worldwide (1). Despite the decreased incidence and mortality rates due to the major improved diagnosis and treatment, the $\leq 5$-year survival rate is $<20 \%$ (1). This may be due to lack of understanding of the mechanisms underlying the development and prognosis of gastric cancer. Therefore, it is urgent to develop effective therapeutic approaches for gastric cancer.

Nuclearreceptor subfamily 1 groupD member $1(\mathrm{REV}-\mathrm{ERB} \alpha)$ belongs to the nuclear hormone receptor family (2), which is abundantly expressed in liver, adipose, muscle and brain tissue. REV-ERB $\alpha$ serves an important role in regulating lipid metabolism, inflammatory responses and circadian rhythm (2-4). Previous studies have demonstrated that REV-ERB $\alpha$ may modulate the proliferation and apoptosis of HER $2^{+}$breast cancer cells, which is associated with poor clinical outcomes and survival $(5,6)$. However, to the best of our knowledge, there are no studies regarding the regulation of REV-ERB $\alpha$ in gastric cancer. It is also unknown whether REV-ERB $\alpha$ alterations are associated with the clinicopathological factors and prognosis of human gastric cancer. We hypothesize that the levels of REV-ERB $\alpha$ in gastric cancer are altered compared with normal tissues, and is associated with the clinicopathological features and prognosis of this disease. To examine this hypothesis, samples from patients who were diagnosed with gastric cancer were utilized, and the REV-ERB $\alpha$ gene and protein levels in normal and cancer tissues in those patients were compared. The associations between REV-ERB $\alpha$ expression with the Tumor-Node-Metastasis (TMN) stages and survival times were also analyzed in patients with gastric cancer. Finally, human gastric cancer cells were treated with REV-ERB $\alpha$ activator GSK4112 to determine its effects on apoptosis. Conclusively, the reduction of REV-ERB $\alpha$ was associated with clinical features and prognosis in gastric cancer, and REV-ERB $\alpha$ agonist resulted in apoptosis in gastric cancer cells.

\section{Materials and methods}

Patients and tissues collection. All samples were obtained from 74 patients with diagnosed gastric cancer who underwent 
surgery (surgical resection) at The First Affiliated Hospital of Anhui Medical University in 2014, as previously described (7). The median age of the study population was 63.4 years (range, 33-84 years) and the sex distribution was 58 males and 16 females. The clinical characteristics are summarized in Table I. None of the patients had received any other therapies, including radiotherapy or chemotherapy prior to surgery. The hepatic, renal and bone marrow functions of all patients were normal, and the Eastern Cooperative Oncology Group Performance Status scores were between 0-2 (8). Patients with abnormal function rest results, and those who were pregnant or breast-feeding were excluded.

All patients provided written informed consent. The study protocol was approved by the Clinical Research Ethics Committee of Anhui Medical University (Hefei, China). All methods were performed in accordance with the human ethics guidelines in the clinical research project (9).

Cell culture. The human gastric cancer SGC-7,901 [American Type Culture Collection (ATCC), Manassas, VA, USA] and BGC-823 (ATCC) cell lines and human normal gastric epithelial GES-1 (ATCC) cell line were employed to detect REV-ERB $\alpha$ expression. Cells were maintained in Dulbecco's modified Eagle's medium (DMEM; Gibco; Thermo Fisher Scientific, Inc., Waltham, MA, USA) containing high glucose, $1 \mathrm{mmol} / \mathrm{l} \mathrm{L}$-glutamine, pyridoxine hydrochloride, $110 \mathrm{mg} / \mathrm{l}$ sodium pyruvate and bicarbonate. Additionally, 10\% heat inactivated foetal calf serum (Clark Bioscience, Richmond, VA, USA), $100 \mathrm{U} / \mathrm{ml}$ penicillin and $100 \mu \mathrm{g} / \mathrm{ml}$ streptomycin were added to the DMEM. Cells were cultured at $37^{\circ} \mathrm{C}$ in a humidified atmosphere of $5 \% \mathrm{CO}_{2}$.

Immunohistochemistry. REV-ERB $\alpha$ expression in human gastric cancer and normal tissues (5 $\mathrm{cm}$ from the tumor site) was measured by immunohistochemistry as described previously (7). Immunohistochemistry was performed on $4-\mu$ m-thick sections from $10 \%$ formalin-fixed paraffin-embedded tissue specimens. Sections were deparaffinized with $100 \%$ xylene at $25^{\circ} \mathrm{C}$ for $10 \mathrm{~min}$ and removed xylene through a graded series (100, 85 and $70 \%$ ethanol) and were subjected to microwaving with $10 \mathrm{~mm}$ citrate buffer $(\mathrm{pH}=6.0)$ at $100^{\circ} \mathrm{C}$ for $5 \mathrm{~min}$. Briefly, the sections were blocked with $3 \%$ hydrogen peroxide and $10 \%$ normal goat serum (Clark Bioscience) each for $10 \mathrm{~min}$ at room temperature, and then incubated with REV-ERB $\alpha$ rabbit antibody (cat no. AB174309; 1:100 dilution; Abcam, Cambridge, MA, USA) overnight at $4^{\circ} \mathrm{C}$. Following incubation with a biotin-conjugated secondary antibody (cat. no. PV6000; 1:100 dilution; ZSGB-BIO; OriGene Technologies, Inc., Beijing, China), the tissue slides were incubated with a streptavidin-biotin horseradish peroxidase complex for $30 \mathrm{~min}$ at room temperature, followed by incubation with 3,3'-diaminobenzidine (ZSGB-BIO; OriGene Technologies, Inc.) for $5 \mathrm{~min}$ at room temperature. The counterstaining with $20 \%$ hematoxylin was then performed for $60 \mathrm{sec}$ at room temperature, and images of stained samples were captured in a single-blinded manner under a fluorescent microscope at a magnification of x200. The relative protein expression of all images was calculated using mean optical density units, and the sequences were analyzed using IPWIN Application software version 6.0.0260 (Media Cybernetics, Inc., Rockville, MD, USA). The staining intensity was scored according to the number of cells: 0 , no staining; $1(\leq 25 \%)$, weakly stained; 2 (25-50\%), moderately stained; or 3 ( $\geq 50 \%$ ), markedly stained. A low REV-ERB $\alpha$ expression was defined as score ' 0 ', ' 1 ' or '2', and a high REV-ERB $\alpha$ expression was defined as score ' 3 '. The patients were divided into two groups: The low expression group $(n=43)$ and high expression group ( $\mathrm{n}=31)$, as summarized in Table I.

Western blot analysis. Gastric tissues and cells were lysed in lysis buffer (25 mM HEPES, $2 \mathrm{mM} \mathrm{MgCl}$, $2 \mathrm{mM}$ DTT, $1 \mathrm{mM}$ EDTA, $1 \mathrm{mM}$ PSMF, $5 \mu \mathrm{g} / \mathrm{ml}$ leupeptin, $\mathrm{pH}$ 7.4). Subsequent to freeze-thawing the suspension liquid containing the extracted protein 3 times, the lysates were centrifuged at $32,869.2 \mathrm{x}$ g at $4^{\circ} \mathrm{C}$ for $30 \mathrm{~min}$. The concentration of all the extracted protein was determined by the BCA assay. The protein extracts $(10 \mu \mathrm{l})$ were separated by $12 \%$ SDS-PAGE and transferred to polyvinylidene fluoride (PVDF) membranes. Following non-specific blocking with $5 \%$ skimmed milk at room temperature for $2 \mathrm{~h}, \mathrm{PVDF}$ membranes were washed 2 times with TBST (TBS contained $0.1 \%$ Tween-20) for 10 min each time. The membranes were then incubated with primary antibodies against: REV-ERB $\alpha$ (rabbit; cat no. AB174309; 1:500 dilution; Abcam); cleaved caspase-3 (mouse; cat no. SC70497; 1:500 dilution; Santa Cruz Biotechnology, Inc., Dallas, TX, USA); B-cell lymphoma 2 (Bcl-2; mouse; cat no. SC23960; 1:500 dilution; Santa Cruz Biotechnology, Inc.); Bcl-2-associated X protein (Bax; mouse; cat no. SC23959; 1:500 dilution; Santa Cruz Biotechnology, Inc.); and $\beta$-actin (mouse; cat no. AB8226; 1:1,000 dilution; Abcam) overnight at $4^{\circ} \mathrm{C}$, and then washed 3 times with TBST for $10 \mathrm{~min}$ each time. The membranes were incubated with the corresponding Goat anti-mouse horseradish peroxidase-conjugated secondary antibody (mouse; cat no. AP124P; 1:1,000 dilution; EMD Millipore, Billerica, MA, USA) or rabbit anti-Goat horseradish peroxidase-conjugated secondary antibody (rabbit; cat no. AP106P; 1:1,000 dilution; EMD Millipore) for $2 \mathrm{~h}$ at $20^{\circ} \mathrm{C}$, and then washed 3 times with TBST again for $10 \mathrm{~min}$ each time. Finally, the detection of the molecules of interest was performed using enhanced chemiluminescence (Beyotime Institute of Biotechnology, Haimen, China). The bands were quantified to calculate relative protein expression levels using Quantity one software version 4.99.5.2.0 (Bio-Rad Laboratories, Inc., Hercules, CA, USA).

Reverse transcription quantitative polymerase chain reaction $(R T-q P C R)$. Total RNA was extracted from human tissues and cells using TRIzol ${ }^{\circledR}$ (Life Technologies; Thermo Fisher Scientific, Inc.) according to the manufacturer's protocol. Total RNA was reverse transcribed by cDNA synthesis using a PrimeScript RT Reagent kit with gDNA Eraser (Perfect Real Time; Takara Bio, Inc., Otsu, Japan) at $37^{\circ} \mathrm{C}$ for $30 \mathrm{~min}$ and $85^{\circ} \mathrm{C}$ for $5 \mathrm{sec}$. qPCR was performed using a 7,900 Thermal Cycler (ABI, Applied Biosystems; Thermo Fisher Scientific, Inc.) with GoTaq ${ }^{\circledR}$ Green Master Mix (Promega Corporation, Madison, WI USA) at an initial denaturation at $95^{\circ} \mathrm{C}$ for $30 \mathrm{sec}$, followed by 40 cycles of denaturation for $5 \mathrm{sec}$ at $95^{\circ} \mathrm{C}$, annealing for $30 \mathrm{sec}$ at $60^{\circ} \mathrm{C}$ and extension for $15 \mathrm{sec}$ at $72^{\circ} \mathrm{C}$. The qPCR primers for REV-ERB $\alpha$ were 5'-ACAGAATCGAACTCTGCACTTCT-3' (forward) 
Table I. Association between REV-ERB $\alpha$ expression and clinicopathological variables.

\begin{tabular}{|c|c|c|c|c|}
\hline \multirow{2}{*}{$\begin{array}{l}\text { Clinicopathological } \\
\text { variables }\end{array}$} & \multirow{2}{*}{$\begin{array}{c}\text { Numbers of } \\
\text { patients, } n(n=74)\end{array}$} & \multicolumn{2}{|c|}{ REV-ERB $\alpha$ expression level, $\mathrm{n}$} & \multirow[b]{2}{*}{ P-value } \\
\hline & & Low $(n=43)$ & High $(n=31)$ & \\
\hline \multicolumn{5}{|l|}{ Sex } \\
\hline Male & 58 & 35 & 23 & 0.322 \\
\hline Female & 16 & 8 & 8 & \\
\hline \multicolumn{5}{|l|}{ Age, years } \\
\hline$<60$ & 23 & 16 & 7 & 0.138 \\
\hline$\geq 60$ & 51 & 27 & 24 & \\
\hline \multicolumn{5}{|l|}{ Primary tumor site } \\
\hline Gastric cardia or fundus & 36 & 22 & 14 & 0.392 \\
\hline Gastric antrum or body & 38 & 21 & 17 & \\
\hline \multicolumn{5}{|l|}{ Diameter of tumor, $\mathrm{cm}$} \\
\hline$<5$ & 31 & 18 & 13 & 0.995 \\
\hline$\geq 5$ & 43 & 25 & 18 & \\
\hline \multicolumn{5}{|l|}{ Level of differentiation } \\
\hline Moderate & 22 & 8 & 14 & 0.009 \\
\hline Poor & 52 & 37 & 15 & \\
\hline \multicolumn{5}{|l|}{ T stage } \\
\hline $\mathrm{T} 1-\mathrm{T} 2$ & 21 & 5 & 16 & 0.001 \\
\hline T3-T4 & 53 & 39 & 14 & \\
\hline \multicolumn{5}{|l|}{ TNM stage } \\
\hline I-II & 18 & 4 & 14 & 0.001 \\
\hline III-IV & 56 & 40 & 16 & \\
\hline \multicolumn{5}{|l|}{ Lymph node metastasis } \\
\hline Present & 58 & 41 & 17 & 0.007 \\
\hline Absent & 16 & 5 & 11 & \\
\hline
\end{tabular}

TNM, Tumor-Node-Metastasis; REV-ERB $\alpha$, nuclear receptor subfamily 1 group D member 1.

and 5'-GGGGAGGGAGGCAGGTATT-3' (reverse) (10). The primers for $\beta$-actin were 5'-CATGTACGTTGCTAT CCAGGC-3' (forward) and 5'-CTCCTTAATGTCACG CACGAT-3 (reverse). The cycle threshold $(\mathrm{Cq})$ values were obtained in each sample. Relative levels of mRNA were determined using the $2^{-\Delta \Delta C \mathrm{q}}$ method (10). $\beta$-actin was used as an internal gene for normalization.

Morphological measurement of apoptosis. The morphological changes associated with apoptosis were assayed using fluorescence microscopy following Hoechst 33258 staining. The number of cells was counted in five random fields under a fluorescence microscope at a magnification of x200. Briefly, SGC-7901 and BGC-823 cells (3,500 cells/well) were fixed for $30 \mathrm{~min}$ at room temperature in $70 \%$ ethanol, followed by Hoechst33258 $(10 \mu \mathrm{g} / \mathrm{ml})$ staining for $2 \mathrm{~min}$ at $37^{\circ} \mathrm{C}$ and then visualization using the UV fluorescence microscope. Apoptotic cells were considered as cells exhibiting nuclear and cytoplasmic shrinkage, chromatin condensation and apoptotic bodies. A minimum of 400 cells were counted, and the percentage of apoptotic cells, or the apoptotic index, was calculated as described previously (11).
Statistical analysis. Data are expressed as the mean \pm standard deviation. Data analysis was performed using SPSS 17.0 software (SPSS, Inc., Chicago, IL, USA). Comparison between different groups was performed using analysis of variance. The Student-Newman-Keuls test was the post-hoc test used following analysis of variance. The $\chi^{2}$ test was utilized to analyze the associations between REV-ERB $\alpha$ expression levels and clinicopathological variables and survival time. A Kaplan-Meier test was utilized to describe survival curves and the log-rank test was used to analyze survival curves. $\mathrm{P}<0.05$ was considered to indicate a statistically significant difference.

\section{Results}

REV-ERB $\alpha$ expression is decreased in human gastric cancer tissues. The REV-ERB $\alpha$ expression levels in normal gastric and mucous gastric cancer tissues, and gastric cancer tissues with different TNM stages, were determined by immunohistochemistry. As demonstrated in Fig. 1A and B, REV-ERB $\alpha$ protein levels were decreased in gastric cancer tissues, which was associated with increased TNM stage. Additionally, REV-ERB $\alpha$ expression in mucous gastric cancer tissues 

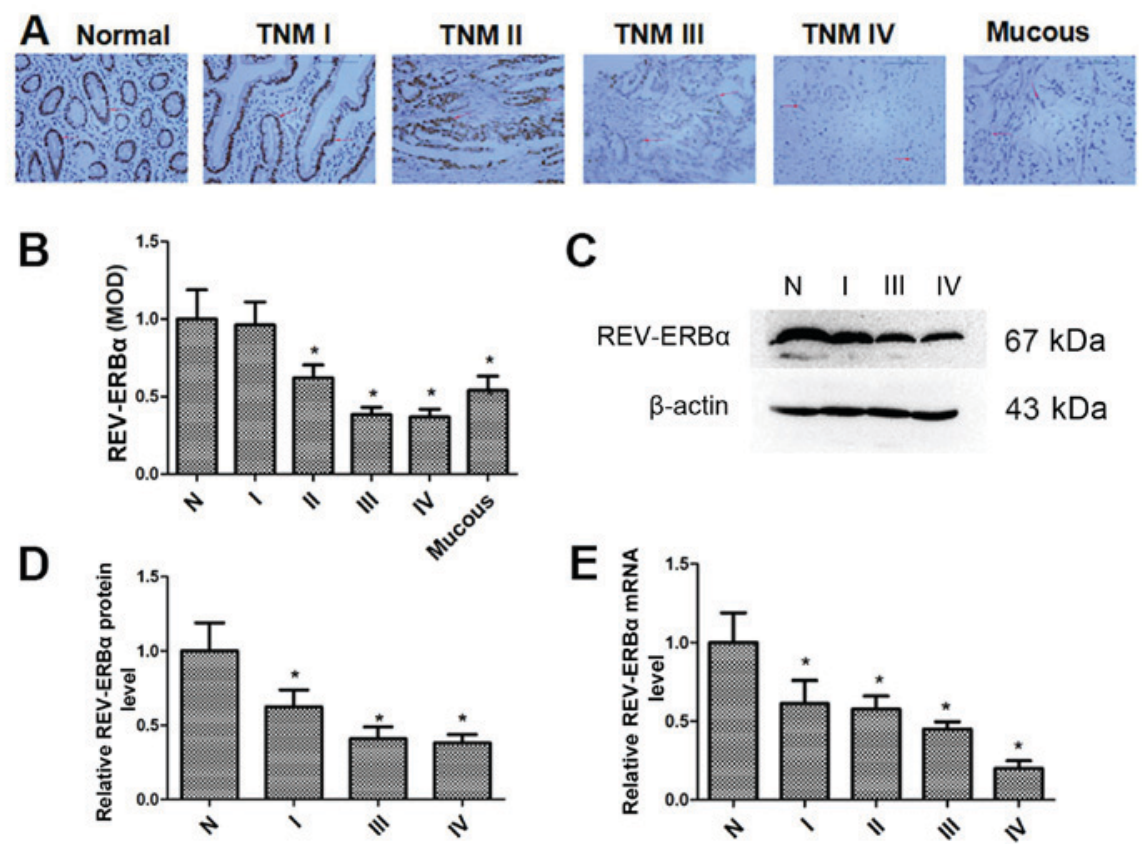

Figure 1. REV-ERB $\alpha$ is decreased in human gastric cancer tissues. (A) The expression of REV-ERB $\alpha$ in normal gastric and mucous gastric cancer tissues, and gastric cancer tissues from patients with TNM I to IV stages was determined by immunohistochemistry. Scale bars=100 $\mu \mathrm{m}$ (original magnification, $\mathrm{x} 200$ ). (B) The MOD indicated the changes in the expression levels of REV-ERB $\alpha$ by immunohistochemistry. (C) The expression of REV-ERB $\alpha$ in normal gastric and gastric cancer tissues from patients with TNM I to IV stages was measured by western blot analysis. $\beta$-actin was used a loading control. (D) Relative protein expression of REV-ERB $\alpha$ was normalized to that of $\beta$-actin in normal gastric and gastric cancer tissues. (E) The mRNA levels of REV-ERB $\alpha$ in normal gastric and gastric cancer tissues from patients with TNM I to IV stages were measured by reverse transcription quantitative polymerase chain reaction. Data are presented as the mean \pm standard deviation. $\mathrm{n}=3$. ${ }^{*} \mathrm{P}<0.05$ vs. normal gastric tissues. $\mathrm{N}$, normal gastric tissues; Mucous, mucous gastric cancer tissues; TNM, Tumor-Node-Metastasis; MOD, mean optical density; REV-ERB $\alpha$, nuclear receptor subfamily 1 group D member 1.

was also decreased compared with normal gastric tissues. Furthermore, the REV-ERB $\alpha$ expression in normal gastric and gastric cancer tissues was confirmed by western blot analysis (Fig. 1C and D). The mRNA levels of REV-ERB $\alpha$ were also measured by RT-qPCR (Fig. 1E). It was identified that the levels of REV-ERB $\alpha$ mRNA were also decreased in gastric cancer tissues, which was associated with incremental TNM stage. These results suggest that REV-ERB $\alpha$ levels are decreased significantly in gastric cancer tissues with higher TNM stages.

Association between REV-ERB $\alpha$ expression and clinicopathological factors in gastric cancer. The association between the REV-ERB $\alpha$ expression and clinicopathological factors was analyzed using immunohistochemistry data (Table I). A low expression of REV-ERB $\alpha$ was significantly associated with poor differentiation $(\mathrm{P}=0.009)$, $\mathrm{T}$ stage $(\mathrm{P}=0.001)$, TMN stage $(\mathrm{P}=0.001)$ and lymph node metastasis $(\mathrm{P}=0.007)$. The results indicated that REV-ERB $\alpha$ level is associated with the progression of gastric cancer.

Association between REV-ERB $\alpha$ expression and survival time of patients with gastric cancer. The different survival times of patients with low and high REV-ERB $\alpha$ expression levels are summarized in Table II. The 3- and 5-year survival times of patients were significantly associated with REV-ERB $\alpha$ expression ( $\mathrm{P}=0.009$ and $\mathrm{P}=0.002$, respectively). The patients with low REV-ERB $\alpha$ expression exhibited poor prognosis $(\mathrm{P}<0.05)$ compared with patients with high REV-ERB $\alpha$ expression (Fig. 2).

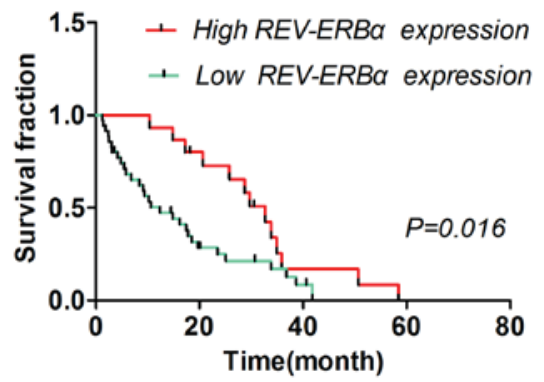

Figure 2. Log-rank test analysis of the association between REV-ERB $\alpha$ expression and survival time of patients with gastric cancer. Patients with high REV-ERB $\alpha$ expression survived (median survival, 32.70 months) significantly longer compared with patients with low REV-ERB $\alpha$ expression (median survival, 12.40 months). REV-ERB $\alpha$, nuclear receptor subfamily 1 group D member 1 .

Cleaved caspase-3 expression is downregulated, whereas the $B c l-2$ expression and $B c l-2 / B a x$ are upregulated, in gastric cancer tissues. To determine whether REV-ERB $\alpha$ was associated with the expression of cleaved caspase-3, Bcl-2 and Bax, western blot analysis was employed to detect the levels of these proteins. As indicated in Fig. 3A and B, the expression levels of cleaved caspase-3 were downregulated in gastric cancer tissues, which was associated with enhanced TNM stage. The Bcl-2 expression levels were upregulated in gastric cancer tissues, which were also associated with enhanced TNM stage. Additionally, the ratio of Bcl-2 to Bax, according to the densitometry of the western blot analysis bands (Fig. 3C), was increased in gastric cancer tissues compared with normal 
Table II. Association between REV-ERB $\alpha$ expression and survival time of patients with gastric cancer.

\begin{tabular}{|c|c|c|c|c|c|c|}
\hline \multirow{2}{*}{$\begin{array}{l}\text { REV-ERB } \alpha \\
\text { expression }\end{array}$} & \multicolumn{3}{|c|}{ 3-year survival time } & \multicolumn{3}{|c|}{ 5-year survival time } \\
\hline & Survival, $\mathrm{n}$ & Mortality, n & P-value & Survival, $\mathrm{n}$ & Mortality, n & P-value \\
\hline Low & 12 & 31 & 0.009 & 8 & 35 & 0.002 \\
\hline High & 18 & 13 & - & 16 & 15 & - \\
\hline
\end{tabular}

REV-ERB $\alpha$, nuclear receptor subfamily 1 group D member 1.
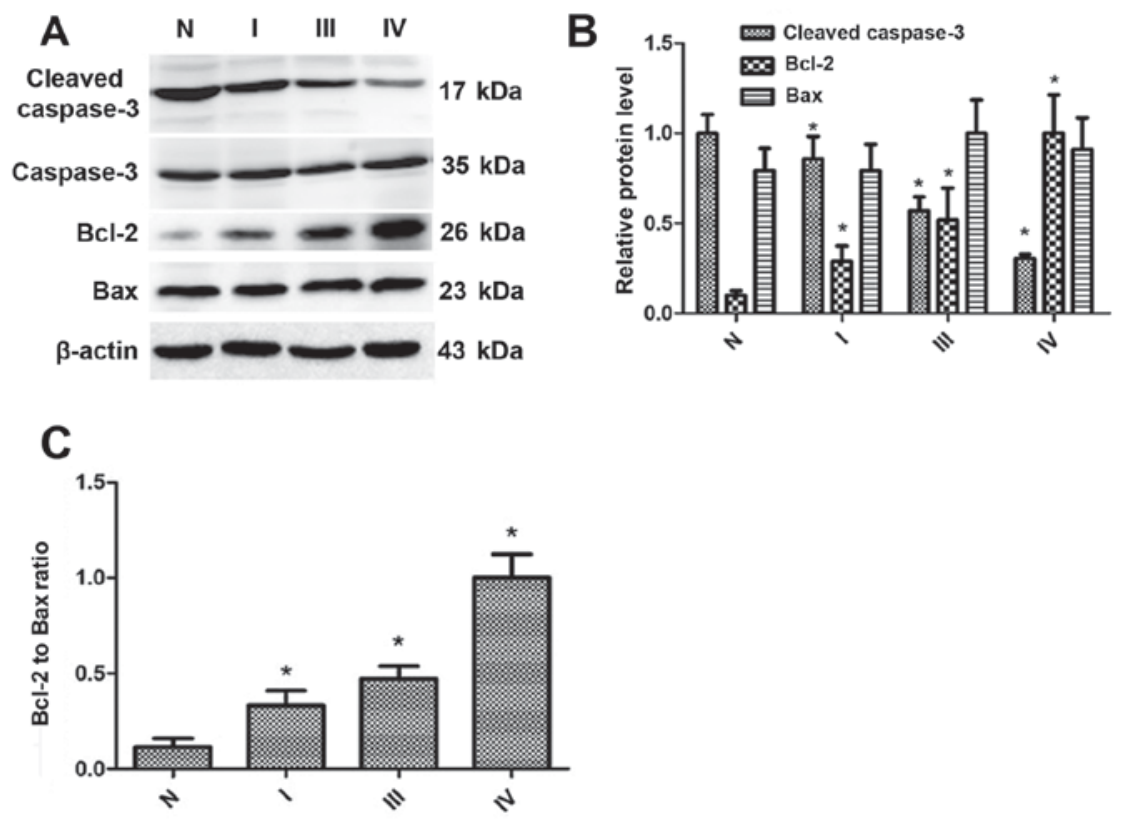

Figure 3. In gastric cancer tissues, the cleaved caspase-3 expression level is downregulated, whereas the expression levels of Bcl-2 and the Bcl-2/Bax ratio are upregulated. (A) Expression of cleaved caspase-3, Bcl-2 and Bax in normal gastric tissues and gastric cancer tissues from patients with TNM I to IV stages was evaluated by western blot analysis. $\beta$-actin was used as a loading control. (B) Relative protein expression of cleaved caspase-3, Bcl-2 and Bax was normalized to that of $\beta$-actin. (C) Densitometry of Bcl-2/Bax ratio according to western blot analysis bands. Data are represented as the mean \pm standard deviation. $\mathrm{n}=3$. * $\mathrm{P}<0.05$ vs. normal gastric tissues. N, normal; Bcl-2, B-cell lymphoma 2; Bax, Bcl-2-associated X protein; TNM, Tumor-Node-Metastasis; REV-ERB $\alpha$, nuclear receptor subfamily 1 group D member 1 .

gastric tissues. Therefore, these results suggest that the level of REV-ERB $\alpha$ is decreased in human gastric cancer, which is associated with decreased levels of apoptosis.

$R E V$-ERB $\alpha$ expression is decreased in human gastric cancer cells, and activation of REV-ERB $\alpha$ causes apoptosis in gastric cancer cells. To additionally investigate the REV-ERB $\alpha$ expression in gastric cancer, GES-1, SGC-7901 and BGC-823 cell lines were employed to determine the expression level of REV-ERB $\alpha$ (Fig. 4A and B). The REV-ERB $\alpha$ expression levels were significantly decreased in SGC-7901 (moderately differentiated) and BGC-823 (undifferentiated) compared with the GES-1 cell line. The mRNA levels of REV-ERB $\alpha$ were also decreased in SGC-7901 and BGC-823 cells compared with the GES-1 cell line (Fig. 4C). Furthermore, SGC-7901 and BGC-823 cells were treated with the REV-ERB $\alpha$ activator GSK4112 (20 and $40 \mu \mathrm{M}$; MedChemExpress, Monmouth Junction, NJ, USA), and it was identified that GSK4112 treatment for $48 \mathrm{~h}$ at $37^{\circ} \mathrm{C}$ caused an increase in apoptosis in a dose-dependent manner (Fig. 5). Therefore, these results suggest that REV-ERB $\alpha$ activation induces apoptosis in human gastric cancer cells.

\section{Discussion}

REV-ERBs were originally regarded as orphan receptors to regulate gene transcription in response to multifarious environmental stimuli (12). The members of REV-ERB family, including REV-ERB $\alpha$ and REV-ERB $\beta$, exhibit abundant and overlapping expression in adipose, muscle, brain and liver tissues (13). However, REV-ERB $\alpha$ is broadly expressed at the similar level in a number of different tissues, whereas REV-ERB $\beta$ is highly expressed in parts of the brain, including the pineal gland and prefrontal cortex, thyroid, uterus and pituitary (12).

REV-ERB $\alpha$ modulates the circadian rhythm by directly activating the expression of key circadian clock genes, including Clock circadian regulator, Brain and muscle ANRT-like 1, 
A

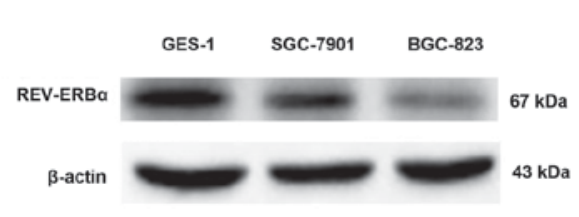

B

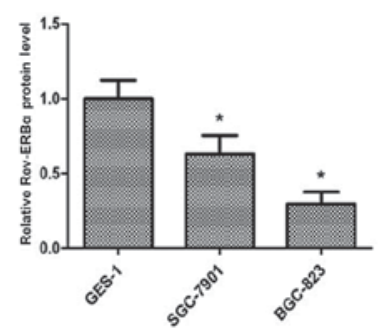

C

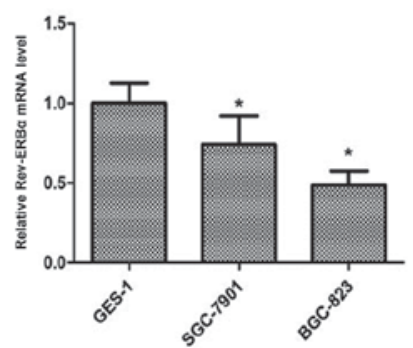

Figure 4. Expression of REV-ERB $\alpha$ is decreased in human gastric cells. (A) Expression of REV-ERB $\alpha$ in the normal gastric epithelial GES-1 cell line and human gastric cancer SGC-7901 and BGC-823 cell lines was measured by western blot analysis. $\beta$-actin was used as a loading control. (B) Relative protein expression of REV-ERB $\alpha$ was normalized to that of $\beta$-actin. (C) The mRNA levels of REV-ERB $\alpha$ was measured by reverse transcription quantitative polymerase chain reaction in the normal gastric epithelial GES-1 cell line and human gastric cancer SGC-7901 and BGC-823 cell lines. Data are presented as the mean \pm standard deviation. $n=3$. "P<0.05 vs. normal gastric epithelial GES-1 cell line. REV-ERB $\alpha$, nuclear receptor subfamily 1 group D member 1.

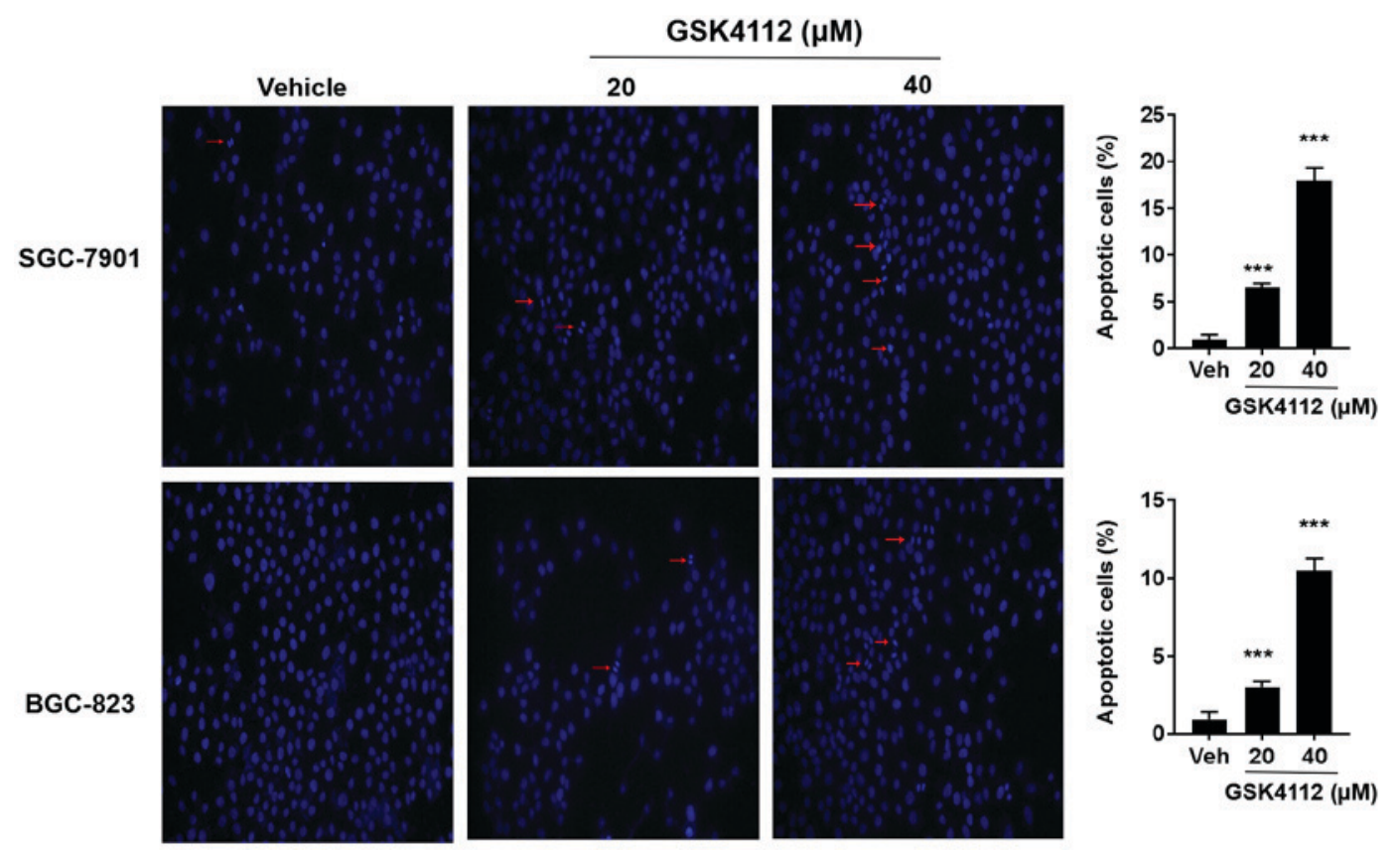

Figure 5. Activation of REV-ERB $\alpha$ causes apoptosis in SGC-7901 and BGC-823 cell lines. SGC-7901 and BGC-823 cells were treated with a REV-ERB activator GSK4112 (20 and $40 \mu \mathrm{M})$ for $48 \mathrm{~h}$. Hoechst33258 staining was performed to detect apoptotic cells that exhibited nuclear and cytoplasmic shrinkage, chromatin condensation and apoptotic bodies using UV fluorescence microscopy (original magnification, x200) and were illustrated using red arrows. Data are represented as the mean \pm standard deviation. $n=4 .{ }^{* * * *} \mathrm{P}<0.001$ vs. Veh. Veh, vehicle; REV-ERB $\alpha$, nuclear receptor subfamily 1 group $\mathrm{D}$ member 1.

Cryptochrome and Period (14-17). Epidemiological data indicate that disruption of the circadian clock is associated with an increased risk of development of breast cancer $(18,19)$. Dysregulation of the circadian clock genes may have complex effects on energy homeostasis, potentially resulting in metabolic disorders including cancer $(20,21)$. The present study identified that REV-ERB $\alpha$ expression was significantly decreased in human gastric cancer tissues, which was associated with different clinicopathological stages. This was in agreement with the results that the levels of $\mathrm{REV}$-ERB $\alpha$ were additionally decreased in undifferentiated BGC-823 cells compared with moderately differentiated SGC-7,901 cells. These data suggest the possibility of REV-ERB $\alpha$ as a biomarker of gastric cancer.

It has also been demonstrated that the REV-ERB $\alpha$ expression leading to apoptosis was affected by circadian rhythms (22). REV-ERB $\alpha$ controls the circadian clock genes and regulates Early growth response 1 expression, causing extensive expression of Tumor protein p73 (p73) (23). p73 activates the transcription of $\mathrm{Bax}$ and $\mathrm{Bcl}-2$, causing the release of cytochrome $\mathrm{c}$ from the mitochondria (24). Apoptosome assembly, and the eventual cleavage and activation of transducer caspase-9, in turn cleaves and activates executioner caspase-3. Hence, the circadian clock has a regulating role in the expression of apoptosis factors (Caspase-3, Bcl-2 and Bax) and the activation of the apoptosis pathway (24). The present study identified that REV-ERB $\alpha$ expression was decreased in human gastric cancer, and that this decrease may protect against apoptosis by decreasing the levels of cleaved caspase-3 and increasing Bcl-2 levels. However, one limitation of the present study is that there were only 74 patients included. A larger human cohort is required to confirm these results. It was also unknown how REV-ERB $\alpha$ regulates the 
apoptosis pathway and expression of apoptosis-associated factors, including cleaved caspase-3, Bcl-2 and Bax, in gastric cancer.

It has been demonstrated previously that REV-ERB $\alpha$ regulates lipid metabolism during proliferation and apoptosis $(2,25,26)$. The preliminary data from the present study suggested that REV-ERB $\alpha$ decreased glycolysis levels in gastric cancer cells (data not shown). Nevertheless, it is unclear whether a REV-ERB $\alpha$-mediated decrease of glycolysis is beneficial for therapy in gastric cancer.

In summary, the present study employed immunohistochemistry, western blot analysis and RT-qPCR methods, and identified that REV-ERB $\alpha$ expression was decreased in human gastric cancer tissues. The data indicated that REV-ERB $\alpha$ expression was significantly associated with poor differentiation, T stage, TMN stage and lymph node metastasis in human gastric cancer. Additionally, the survival time of patients was significantly associated with REV-ERB $\alpha$ expression, suggesting that REV-ERB $\alpha$ may be an independent prognosis factor in gastric cancer. Furthermore, REV-ERB $\alpha$ activation induced apoptosis in human gastric cancer cells. Therefore, REV-ERB $\alpha$ is a potential biomarker for tumor development and prognosis, and a potential therapeutic target for gastric cancer.

\section{Acknowledgements}

Not applicable.

\section{Funding}

The present study was funded by the Natural Science Foundation of Anhui Province (grant no. 1608085MH182).

\section{Availability of data and materials}

The datasets used and/or analyzed during the present study are available from the corresponding author on reasonable request.

\section{Authors' contributions}

XSW and ZW designed the study. NW performed the immunohistochemistry to determine the expression of REV-ERB $\alpha$. XSW and XW conducted the western blot analysis. XW also performed the cell proliferation and morphological measurements of apoptosis. HY performed RT-qPCR to detect the expression of REV-ERB $\alpha$. XSW drafted the manuscript.

\section{Ethics approval and consent to participate}

The study protocol was approved by the Clinical Research Ethics Committee of Anhui Medical University (Hefei, China). Informed consent was obtained from all individual participants included in the study.

\section{Consent for publication}

Written informed consent was obtained from all patients for the publication of their data.

\section{Competing interests}

The authors declare that they have no competing interests.

\section{References}

1. Ferlay J, Soerjomataram I, Dikshit R, Eser S, Mathers C, Rebelo M, Parkin DM, Forman D and Bray F: Cancer incidence and mortality worldwide: Sources, methods and major patterns in GLOBOCAN 2012. Int J Cancer 136: E359-E386, 2015.

2. Cho H, Zhao X, Hatori M, Yu RT, Barish GD, Lam MT, Chong LW, DiTacchio L, Atkins AR, Glass CK, et al: Regulation of circadian behaviour and metabolism by REV-ERB- $\alpha$ and REV-ERB- $\beta$. Nature 485: 123-127, 2012.

3. Mazzoccoli G, Cai Y, Liu S, Francavilla M, Giuliani F, Piepoli A, Pazienza V, Vinciguerra M, Yamamoto $\mathrm{T}$ and Takumi T: REV-ERB $\alpha$ and the clock gene machinery in mouse peripheral tissues: A possible role as a synchronizing hinge. J Biol Regul Homeost Agents 26: 265-276, 2012.

4. Vieira E, Merino B and Quesada I: Role of the clock gene Rev-erb $\alpha$ in metabolism and in the endocrine pancreas. Diabetes Obes Metab 17 (Suppl 1): S106-S114, 2015.

5. Kourtidis A, Jain R, Carkner RD, Eifert C, Brosnan MJ and Conklin DS: An RNA interference screen identifies metabolic regulators NR1D1 and PBP as novel survival factors for breast cancer cells with the ERBB2 signature. Cancer Res 70: 1783-1792, 2010.

6. Ka NL, Na TY, Na H, Lee MH, Park HS, Hwang S, Kim IY, Seong JK and Lee MO: NR1D1 recruitment to sites of DNA damage inhibits repair and is associated with chemosensitivity of breast cancer. Cancer Res 77: 2453-2463, 2017.

7. Wang Z, Xiong F, Wang X, Qi Y, Yu H, Zhu Y and Zhu H: Nuclear receptor retinoid-related orphan receptor alpha promotes apoptosis but is reduced in human gastric cancer. Oncotarget 8: 11105-11113, 2017.

8. Yuan SQ, Nie RC, Chen YM, Qiu HB, Li XP, Chen XJ, Xu LP, Yang LF, Sun XW, Li YF, et al: Glasgow Prognostic Score is superior to ECOG PS as a prognostic factor in patients with gastric cancer with peritoneal seeding. Oncol Lett 15: 4193-4200, 2018.

9. Wang Z, Si X, Xu A, Meng X, Gao S, Qi Y, Zhu L, Li T, Li W and Dong L: Activation of STAT3 in human gastric cancer cells via interleukin (IL)-6-type cytokine signaling correlates with clinical implications. PLoS One 8: e75788, 2013.

10. Livak KJ and Schmittgen TD: Analysis of relative gene expression data using real-time quantitative PCR and the 2(-Delta Delta C(T)) methods. Methods 25: 402-408, 2001.

11. Wang Z, Dong L, Zhen Y, Wang Y, Qi D, Xu A, Meng X and Li W: Astragalus extract inhibits proliferation but enhances apoptosis in gastric cancer. Pak J Pharm Sci 29: 1473-1482, 2016.

12. Sitaula S, Zhang J, Ruiz F and Burris TP: Rev-erb regulation of cholesterologenesis. Biochem Pharmacol 131: 68-77, 2017.

13. Wu Y, Qi Y, Liu H, Wang X, Zhu H and Wang Z: AMPK activator AICAR promotes 5-FU-induced apoptosis in gastric cancer cells. Mol Cell Biochem 411: 299-305, 2016.

14. Partch CL, Green CB and Takahashi JS: Molecular architecture of the mammalian circadian clock. Trends Cell Biol 24: 90-99, 2014.

15. Marciano DP, Chang MR, Corzo CA, Goswami D, Lam VQ, Pascal BD and Griffin PR: The therapeutic potential of nuclear receptor modulators for treatment of metabolic disorders: PPAR $\gamma$, RORs, and Rev-erbs. Cell Metab 19: 193-208, 2014.

16. Lee J, Lee S, Chung S, Park N, Son GH, An H, Jang J, Chang DJ, Suh YG and Kim K: Identification of a novel circadian clock modulator controlling BMAL1 expression through a ROR/REV-ERB-response element-dependent mechanism. Biochem Biophys Res Commun 469: 580-586, 2016.

17. Mazzoccoli G, De Cata A, Piepoli A and Vinciguerra M: The circadian clock and the hypoxic response pathway in kidney cancer. Tumour Biol 35: 1-7, 2014.

18. Reszka E and Przybek M: Circadian genes in breast cancer. Adv Clin Chem 75: 53-70, 2016.

19. Wang Y, Kojetin D and Burris TP: Anti-proliferative actions of a synthetic REV-ERB $\alpha / \beta$ agonist in breast cancer cells. Biochem Pharmacol 96: 315-322, 2015.

20. Fu L and Kettner NM: The circadian clock in cancer development and therapy. Prog Mol Biol Transl Sci 119: 221-282, 2013. 
21. Gutierrez-Martinez P, Rossi DJ and Beerman I: DNA damage and aging around the clock. Trends Mol Med 22: 635-637, 2016.

22. Chomez P, Neveu I, Mansén A, Kiesler E, Larsson L, Vennström B and Arenas E: Increased cell death and delayed development in the cerebellum of mice lacking the rev-erbA(alpha) orphan receptor. Development 127: 1489-1498, 2000.

23. Tao W, Wu J, Zhang Q, Lai SS, Jiang S, Jiang C, Xu Y, Xue B, Du J and Li CJ: EGR1 regulates hepatic clock gene amplitude by activating Per1 transcription. Sci Rep 5: 15212 . 2015.

24. Lee JH and Sancar A: Circadian clock disruption improves the efficacy of chemotherapy through p73-mediated apoptosis. Proc Natl Acad Sci USA 108: 10668-10672, 2011.
25. Bugge A, Feng D, Everett LJ, Briggs ER, Mullican SE, Wang F, Jager J and Lazar MA: Rev-erb $\alpha$ and Rev-erb $\beta$ coordinately protect the circadian clock and normal metabolic function. Genes Dev 26: 657-667, 2012.

26. He Y, Lin F, Chen Y, Tan Z, Bai D and Zhao Q: Overexpression of the circadian clock gene rev-erb $\alpha$ affects murine bone mesenchymal stem cell proliferation and osteogenesis. Stem Cells Dev 24: 1194-1204, 2015.

This work is licensed under a Creative Commons Attribution-NonCommercial-NoDerivatives 4.0 International (CC BY-NC-ND 4.0) License. 